FINANCIAL: Jurnal Akuntansi

Published by Program Studi Akuntansi STIE Sultan Agung

Volume 6-Nomor 1, Juni 2020, (HIm 17-23)

ISSN-P: 2502-4574, ISSN-E: 2686-2581

Available online at: https://financial.ac.id/index.php/financial

\title{
ANALISIS PERBANDINGAN KINERJA KEUANGAN PADA BANK BUMN DAN SWASTA PERIODE 2016-2018
}

\author{
Lailani Fitria $^{1)}$,Hefi Zuswita ${ }^{2)}$, Rispa Eliza ${ }^{3)}$ \\ 1,2,3 Program Studi Akuntansi, STIE Tuah Negeri, Dumai, Indonesia \\ Email: ${ }^{1}$ sister.lanif@gmail.com, ${ }^{2}$ hefizuswita@gmail.com, ${ }^{3}$ rispaeliza64@gmail.com
}

\begin{abstract}
Abstrak
Fenomena perlambatan pertumbuhan laba pada bank pelat merah yang disebabkan tekanan ketidakpastian ekonomi global dan domestik namun disisi lain performa keuangan pada bank swasta salah satunya BCA yang tetap dapat mempertahankan keunggulan kinerja keuangannya menjadi menarik untuk diteliti lebih lanjut. Penelitian ini bertujuan untuk mengetahui rasio keuangan bank milik pemerintah diantaranya : Bank Mandiri ; Bank BRI; Bank BNI; dan Bank BTN dan rasio keuangan bank milik swasta nasional yaitu : BCA; Bank Danamon; Bank Mega; Bank MNC; Bank Permata ; dan Bank Sinarmas pada tahun 2016 - 2018 ditinjau dari aspek rasio quick ratio(QR), banking ratio(BR), dan loan to assets ratio(LAR), dan return on equity(ROE). Penelitian ini menggunakan metode komparatif dengan metode analisis runtun waktu (time series) dan menghitung rata-rata nilai pada tiap rasio keuangan. Hasil penelitian menunjukkan bahwa dilihat dari rasio QR menunjukkan Bank BUMN dan Bank Swasta memiliki nilai rata-rata sama yaitu sebesar 0,11 persen. Rasio BR dari Bank BUMN memperlihatkan perbedaan jumlah rata-rata adalah sebesar 0,91 persen kemudian dibandingkan rata-rata pada Bank SWASTA yang tidak terpaut jauh perbedaannya yaitu sebesar 0,83 persen. Rasio LAR dari Bank BUMN adalah sebesar 8,71 persen, sedangkan rata-rata pada Bank SWASTA sebesar 7,64 persen, terdapat selisih sebesar 1,07 persen Sedangkan rasio ROE pada Bank BUMN menunjukkan rata-rata sebesar 0,16 dibandingkan dengan jumlah rata-rata Bank SWASTA yang terdapat banyak selisih sebanyak 0,13 persen yaitu sebesar 0,03 persen.
\end{abstract}

Kata Kunci: quick ratio $(Q R)$, banking ratio(BR), loan to assets ratio( $L A R)$, return on equity $(R O E)$

\section{COMPARATIVE ANALYSIS OF FINANCIAL PERFORMANCE IN BUMN AND PRIVATE BANKS PERIOD 2016-2018}

\begin{abstract}
The slowing down of profit growth phenomenon in the state-owned banks caused by pressure uncertainty of global and domestic economies, but the other hand financial performance in the Bank is only BCA which is still able to maintain the primacy of its financial performance becomes to be interested in further research. This research aims to examine the financial ratio of Government Bank among others : Mandiri Bank; BRI Bank; BNI Bank; and BTN Bank and financial ratio of National Private Banks are ; BCA ; Danamon Bank; Mega Bank; MNC Bank ; Permata Bank; and Sinarmas Bank in 2016-2018 in terms of aspect ratio quick ratio (QR), banking ratio $(B R)$ and loan to assets ratio (LAR), and return on equity ( ROE). This research uses a comparative method with time series analysis method and calculates the average value of each financial ratio. The results of study indicate that the QR ratio signifies BUMN Bank and Private Banks have the same average value of 0.11 percent. BR ratio of state owned bank indicates the difference in the average amount 0.91 percent and then compared the average to the PRIVATE Bank which is not related the difference is 0.83 percent. LAR ratio of state owned bank is 8.71 percent while the average of private bank is 7.64 percent, there is a difference of 1.07 percent. While the ROE ratio of state-owned banks indicates an average 0.16 compared to the average number private banks. Which there are many differences as much 0.13 percent which is equal to 0.03 percent. Keywords: quick ratio $(Q R)$, banking ratio $(B R)$, loan to assets ratio( $L A R)$, return on equity $(R O E)$
\end{abstract}

Article History: Received: 16 Jan 2020 Revised: 16 Mar 2020 Accepted: 08 Apr 2020 


\section{PENDAHULUAN}

Bank adalah sebuah badan usaha yang menghimpun dana dari masyarakat dalam bentuk simpanan dan menyalurkannya kepada masyarakat dalam bentuk kredit dan atau bentuk-bentuk lain dengan tujuan untuk meningkatkan taraf hidup orang banyak (Indonesia, 1998).

Di Indonesia jika dilihat dari jenis bank dilihat dari kepemilikan diantaranya : bank milik pemerintah, bank milik swasta nasional, bank milik koperasi dan bank milik asing. Bank milik pemerintah baik akta pendirian maupun modalnya dimiliki oleh pemerintah, sehingga seluruh keunntungan bank ini dimiliki oleh pemerintah pula. Bank milik swasta nasional adalah seluruh atau sebagian besarnya dimiliki oleh swasta nasional serta akta pendiriannya pun didirikan oleh swasta, begitu pula pembagian keuntungan untuk keuntungan swasta pula. Bank milik koperasi adalah saham bank yang dimiliki oleh perusahaan yang berbadan hukum koperasi. Kemudian bank milik asing merupakan cabang dari bank yang ada diluar negeri baik milik swasta asing atau pemerintah asing sehingga jelas kepemilikannya dimiliki oleh pihak luar negeri (Bustari M, Rose R, 2016).

Pada bank yang dimiliki oleh negara maupun bank milik swasta harus mampu mengelola dana yang dimiliki, keunggulan, dan kelemahannya untuk menghasilkan keuntungannya. Kinerja keuangan dibutuhkan untuk mengetahui seberapa besar dampaknya terhadap strategi usaha pada industri perbankan. Jika kinerja keuangan bank baik, maka perekonomian di Indonesia baik begitu juga sebaliknya, jika kinnerja keuangan perbankan tidak baik maka perekonomian juga tidak baik. Salah satu faktor penentu dalam menentukan perekonomian yang baik dapat dilihat dari pertumbuhan laba industri perbankan, pada tahun 2019 yang lalu pertumbuhan laba empat bank pelat merah tercatat mengalami perlambatan. Keuntungan Bank Mandiri sebesar 9,9\% pertahun dibandingkan tahun sebelumnya sebesar 21,2\%. BRI sebesar 6,2\% dari $11,6 \%$. Lalu BNI mengalami peningkatan laba dari $10,3 \%$ menjadi $12,8 \%$. Sementara itu BTN mendapatkan rapor merah, laba bersih turun drastis hingga $92,5 \%$ dari $\mathrm{Rp}$ 2,8 triliun menjadi hanya Rp 209,3 miliar. Berbanding terbalik dengan sektor swasta salah satunya BCA yang berhasil mencatat kinerja yang baik pada tahun 2019 PPOP sebesar $15,5 \%$ yang ditopang oleh pertumbuhan laba operasional sebesar $13,6 \%$.

Pertumbuhan laba pada bank BUMN melambat disebabkan oleh kenaikan kredit yang bermasalah seperti penurunan margin bunga bersih karena kenaikan biaya dana, kemudian kenaikan biaya pencadangan akibat kenaikan rasio kredit bermasalah dan kenaikan beban bunga. Di lain sisi performa keuangan pada bank swasta, salah satunya adalah BCA yang seakan tidak terganggu tekanan ketidakpastian ekonomi global dan domestik tetap mempertahankan keunggulan kinerja keuangannya dalam perbankan di Indonesia.

Pada prinsipnya persaingan di industri perbankan didominasi oleh persaingan untuk mendapatkan dana dari masyarakat dan merebut pangsa pasar kredit pembiayaan usaha (Saragih, 2017). Sehingga mengukur kinerja keuangan dengan bantuan rasio seperti likuiditas dan rentabilitas akan sangat membantu bank dalam mengetahui kemampuan bank dalam menghasilkan laba dan mengukur 
tingkat efektifitas manajemen dalam menjalankan operasional perusahaannya.

Berdasarkan penelitian terdahulu, rasio likuiditas PT Bank BRI, Tbk dengan indikator quick ratio, banking ratio, dan assets to loan ratio diperoleh hasil bahwa kinerja keuangan bank BRI dari tahun 2015-2017 dalam keadaan likuid karena ketiga indikator tersebut memenuhi standar ketetapan rasio Bank Indonesia. Rasio Profitabilitas PT Bank BRI, Tbk dengan indikator net profit margin, return on equity dan return on total assets mengalami penurunan. Penurunan yang signifikan terjadi pada ROE di tahun 2016 sebesar 4,6\% yang disebabkan oleh ekuitas bank yang meningkat drastis sebesar Rp.33.685.411.-. (Sepang FV, 2019)

Senada dengan penelitian terdahulu mengenai kinerja keuangan bank BUMN. Hasil penelitian rasio LDR Bank Mandiri dengan BTN, Bank BRI dengan BTN, Bank BNI dengan BTN memiliki perbandingan yang signifikan. Rasio ROE Bank Mandiri dengan BRI, Bank Mandiri dengan BNI, Bank Mandiri dengan BTN, Bank BRI dengan BNI, Bank BRI dengan BTN memiliki perbandingan yang signifikan. Saran dari penulis yaitu Bank Mandiri, BRI, dan BNI harus mempertahankan serta meningkatkan kinerjaagar boleh lebih berkembang. Untuk Bank BTN harus lebih berkembang lagi agar tidak tertinggal dengan bank lainnya. (Bawendu et al., 2017)

Rumusan masalah penelitian ini adalah bagaimanakah perbandingan kinerja keuangan pada bank bumn dan swasta yang terdaftar di BEI 2016-2018. Dengan menggunakan analisis runtun waktu yang digunakan untuk mengevaluasi kinerja keuangan dari rasio likuiditas dan profitabilitas maka diharapkan pada bank tersebut selama beberapa periode tertentu dapat mengetahui arah perkembangan keuangannya sehingga dapat melakukan tindakan atau solusi yang sesuai di masa mendatang jika terjadi kendala yang serupa.

\section{LANDASAN TEORI}

Salah satu metode yang bisa digunakan untuk menganalisa laporan keuagan adalah analsis rasio. Pada umumnya perhitungan rasio-rasio data keuangan adalah guna menilai kinerja perusahaan di masa lalu, saat ini dan berbagai kemungkinannya di masa depan. (Hantono, 2018).

Analisis rasio menurut (Sugiono and Untung, 2008) adalah suatu angka yang menunjukkan hubungan antara unsurunsur dalam laporan keuangan. Hubungan tersebut dinyatakan dalam bentuk matematis yang sederhana.

Menurut (Kariyoto, 2017) rasio keuangan secara umum dinyatakan dalam satuan persentase (\%) atau "kali". Komparasi laporan keuangan dalam masa dua atau tiga tahun dapat dilakukan dengan menghitung perubahan dari tahun ke tahun, baik untuk jumlah absolut (rupiah) maupun untuk persentase.

Rasio likuiditas mengukur kemampuan bank untuk memenuhi kewajiban finansial jangka pendek. Rasio likuiditas dihitung berdasarkan informasi yang terdapat dalam laporan keuangan neraca. (Arifin J, 2006) Kendala yang dihadapi bank dalam mengatur kebijakan likuiditas antara lain adalah:

a. Ketetapan yang diberlakukan oleh bank sentral tentang legal reserve requirement

b. Terdapat dilema antara likuiditas dengan profitabilitas, semakin tinggi 
likuiditas maka idle fund semakin besar dan profitabilitas rendah

c. Adanya working reserve requirement yaitu kebutuhan aktiva lancar (cash assets).

Rasio yang digunakan untuk menghitung likuiditas bank dengan pendekatan kuantitatif adalah sebagai berikut :

a) Quick ratio

Digunakan untuk mengetahui kemampuan bank dalam membayar kembali kewajiban kepada deposan dengan aktiva lancar yang dimilikinya.

$$
Q R=\frac{\text { cash assets }}{\text { total deposit }} \times 100 \%
$$

b) Banking ratio

Digunakan untuk mengetahui kemampuan pihak bank dalam membayar kembali kewajiban deposan dengan bersumber dari penarikan kembali kredit yang diberikan kepada debitur.

$$
B R=\frac{\text { total loan }}{\text { total deposit }} \times 100 \%
$$

c) Loan to assets ratio

Digunakan untuk mengukur kemampuan pihak bank dalam memenuhi pemintaan kredit debitur dengan aktiva yang dimilikinya.

$$
L A R=\frac{\text { total loan }}{\text { total assets }} \times 100 \%
$$

Rasio profitabilitas atau sering juga disebut dengan istilah rasio rentabilitas adalah mengukur seberapa besar kemampuan bank memperoleh laba sehubungan dengan aktivitas yang dijalankannya. Rasio yang digunakan menghitung profitabilitas dengan pendekatan kuantitatif adalah return on equity yaitu Mengukur kemampuan manajemen bank dalam menghasilkan pendapatan berdasarkan aktiva yang dikuasinya, dengan rumus sebagai berikut :

$$
R O E=\frac{\text { laba setelah pajak }}{\text { total modal inti }} \times 100 \%
$$

\section{METODE}

Dalam metode ini, jenis penelitian menggunakan metode komparatif yaitu membandingkan keberadaan satu variabel atau lebih pada dua atau lebih sampel yang berbeda pada waktu yang berbeda (Sandu and Ali, 2015). Kemudian variabel yang digunakan adalah kinerja keuangan yaitu apakah terdapat perbedaan kinerja keuangan bank pemerintah dan bank swasta. Kinerja keuangan diukur dengan menggunakan rasio keuangan bank milik pemerintah diantaranya : Bank Mandiri ; Bank BRI; Bank BNI; dan Bank BTN dan rasio keuangan bank milik swasta nasional yaitu : BCA; Bank Danamon; Bank Mega; Bank MNC; Bank Permata ; dan Bank Sinarmas

Analisis yang digunakan adalah runtun waktu (time series) adalah membandingkan rasio pada waktu berbeda. (Wijaya, 2017). Jenis data yang digunakan adalah data sekunder, maka pada penelitian ini teknik pengumpulan data pada penelitian ini adalah dengan dokumentasi. Pengumpulan data dengan dokumentasi yaitu dilakukan dengan meneliti dan mempelajari dokumen dokumen yang relevan dengan kepentingan penelitian. Dokumen yang menjadi acuan adalah laporan keuangan perbankan 2016-2018.

\section{HASIL DAN PEMBAHASAN}

Berdasarkan data laporan keuangan yang tersaji dalam neraca dan laporan laba rugi selama periode tahun 2016 sampai 2018 setelah diaudit, maka selanjutnya akan disajikan perhitungan rasio likuiditas 
dan profitabilitas untuk menilai tingkat kesehatan pada bank mandiri, bank bri, bank bni, bank btn, bank bca, bank danamon, bank mega, bank mnc, bank permata, dan bank sinarmas.

Tabel 1 : Rasio Keuangan pada bank BUMN tahun 2016 - 2018

\begin{tabular}{|c|c|c|c|c|c|}
\hline $\begin{array}{c}\text { BANK } \\
\text { BUMN }\end{array}$ & TAHUN & QR & BR & LAR & ROE \\
\hline \multirow{4}{*}{ BANK BNI } & 2016 & 0,11 & 0,92 & 8,26 & 0,14 \\
\cline { 2 - 6 } & 2017 & 0,13 & 0,87 & 6,73 & 0,15 \\
\cline { 2 - 6 } & 2018 & 0,11 & 0,91 & 8,17 & 0,13 \\
\hline \multirow{4}{*}{ BANK BRI } & 2016 & 0,12 & 0,85 & 7,00 & 0,03 \\
\cline { 2 - 6 } & 2017 & 0,11 & 0,76 & 7,22 & 0,18 \\
\cline { 2 - 6 } & 2018 & 0,12 & 0,75 & 6,46 & 0,16 \\
\hline \multirow{3}{*}{ BANK BTN } & 2016 & 0,08 & 0,99 & 12,49 & 0,29 \\
\cline { 2 - 6 } & 2017 & 0,08 & 0,99 & 12,80 & 0,14 \\
\hline \multirow{3}{*}{\begin{tabular}{c} 
BANK \\
\cline { 2 - 6 }
\end{tabular}} & 2016 & 0,09 & 1,01 & 11,82 & 0,12 \\
\cline { 2 - 6 } & 2017 & 0,11 & 0,94 & 8,20 & 0,14 \\
\hline & 2018 & 0,13 & 1,02 & 7,84 & 0,13 \\
\hline RANDIRI & & 0,11 & 0,91 & 8,71 & 0,16 \\
\hline
\end{tabular}

Sumber : data diolah 2019

Berdasarkan tabel diatas dari keempat bank BUMN, BNI dan Bank Mandiri memiliki QR tertinggi sebesar 0,13 masing-masing pada tahun 2017 dan 2018. Sedangkan BRI dan BTN tertinggi masing-masing sebesar 0,12 dan 0,09. Ini menunjukkan bahwa BTN harus memperbaiki kinerja kemampuan bank dalam membayar kembali kewajiban kepada deposan dengan aktiva lancar yang dimilikinya.

Bank Mandiri memiliki BR yang paling tinggi sebesar 1,02 pada tahun 2018 dibanding BTN sebesar 1,01 pada tahun yang sama. Sedangkan BNI dan BRI masing-masing sebesar 0,92 pada tahun 2016 dan 0,85 pada tahun 2016. Ini menunjukkan bahwa kinerja keuangan bank BUMN dilihat dari rasio BR hampir mendekati ketentuan BI yaitu 1,5.

Copyright (C) 2020, FINANCIAL: Jurnal Akuntansi
BTN memiliki LAR tertinggi pada 3 tahun berturut-turut yaitu 12,49 pada tahun 2016, sebesar 12,80 di tahun 2017, dan terakhir 11,82 di tahun 2018 . Dibandingkan dengan BNI sebesar 8,26 pada tahun 2016, kemudian Bank Mandiri sebesar 8,20 di tahun 2017, dan terakhir BRI sebesar 7,22 pada tahun 2017. Ini menunjukkan bahwa agar BRI meningkatkan kemampuan pihak bank dalam memenuhi pemintaan kredit debitur dengan aktiva yang dimilikinya.

BTN dan Bank Mandiri memiliki ROE tertinggi masing-masing sebesar 0,29 pada tahun 2016 dan 0,26 pada 2016. Berbanding terbalik dengan BRI dan BNI yang masing-masing memiliki nilai ROE sebesar 0,18 pada tahun 2017 dan 0,15 pada tahun 2017. Apabila ROE semakin tinggi maka semakin baik produktivitas asset dalam memperoleh keuntungan.

Tabel 2 : Rasio Keuangan pada bank SWASTA tahun 2016 - 2018

\begin{tabular}{|c|c|c|c|c|c|}
\hline $\begin{array}{c}\text { BANK } \\
\text { SWASTA }\end{array}$ & TAHUN & QR & BR & LAR & ROE \\
\hline \multirow{3}{*}{ BANK BCA } & 2016 & 0,13 & 0,75 & 5,85 & 0,24 \\
\hline & 2017 & 0,12 & 0,80 & 6,55 & 0,18 \\
\hline & 2018 & 0,12 & 0,82 & 7,11 & 0,18 \\
\hline \multirow{3}{*}{$\begin{array}{c}\text { BANK } \\
\text { DANAMON }\end{array}$} & 2016 & 0,11 & 0,86 & 8,07 & 0,08 \\
\hline & 2017 & 0,11 & 0,88 & 7,75 & 0,09 \\
\hline & 2018 & 0,10 & 0,92 & 9,53 & 0,10 \\
\hline \multirow{3}{*}{$\begin{array}{l}\text { BANK } \\
\text { MEGA }\end{array}$} & 2016 & 0,10 & 0,54 & 5,19 & 0,10 \\
\hline & 2017 & 0,10 & 0,56 & 5,82 & 0,11 \\
\hline & 2018 & 0,08 & 0,67 & 8,22 & 0,10 \\
\hline \multirow{3}{*}{$\begin{array}{l}\text { BANK } \\
\text { MNC }\end{array}$} & 2016 & 0,11 & 1,78 & 16,14 & 0,01 \\
\hline & 2017 & 0,10 & 0,77 & 7,75 & $-0,54$ \\
\hline & 2018 & 0,09 & 0,82 & 8,94 & 0,03 \\
\hline \multirow{3}{*}{$\begin{array}{c}\text { BANK } \\
\text { PERMATA }\end{array}$} & 2016 & 0,11 & 0,71 & 6,55 & $-0,34$ \\
\hline & 2017 & 0,10 & 0,79 & 7,72 & 0,03 \\
\hline & 2018 & 0,10 & 0,82 & 7,90 & 0,04 \\
\hline \multirow{3}{*}{$\begin{array}{c}\text { BANK } \\
\text { SINARMAS }\end{array}$} & 2016 & 0,14 & 0,74 & 5,46 & 0,08 \\
\hline & 2017 & 0,14 & 0,85 & 6,20 & 0,07 \\
\hline & 2018 & 0,13 & 0,87 & 6,71 & 0,0025 \\
\hline Rata-rata & & 0,11 & 0,83 & 7,64 & 0,03 \\
\hline
\end{tabular}


Sumber : data diolah 2019

Berdasarkan tabel diatas dari keenam bank SWASTA, Bank Sinarmas memiliki QR tertinggi sebesar 0,14 selama dua tahun berturut-turut yang masingmasing pada tahun 2016 dan 2017. Sedangkan Bank Mega sebesar 0,08. Ini menunjukkan bahwa Bank Mega harus memperbaiki kinerja kemampuan bank dalam membayar kembali kewajiban kepada deposan dengan aktiva lancar yang dimilikinya.

Bank MNC memiliki BR yang paling tinggi sebesar 1,78 pada tahun 2016 dibanding Bank Danamon sebesar 0,92 pada tahun 2018. Sedangkan Bank Mega adalah sebesar 0,54 pada tahun 2016. Ini menunjukkan bahwa kinerja keuangan bank MNC dilihat dari rasio BR melampaui ketentuan BI yaitu 1,5.

Bank MNC memiliki LAR tertinggi pada tahun 2016 yaitu 16,14. Dibandingkan dengan Bank Mega sebesar 5,19 pada tahun 2016, kemudian BCA sebesar 5,85 di tahun 2016, dan terakhir Bank Sinarmas sebesar 5,46 pada tahun 2016. Ini menunjukkan bahwa agar Bank MNC meningkatkan kemampuan pihak bank dalam memenuhi pemintaan kredit debitur dengan aktiva yang dimilikinya.

BCA memiliki ROE tertinggi sebesar 0,24 pada tahun 2016. Berbanding terbalik dengan Bank MNCyang memiliki nilai ROE sebesar -0,54 pada tahun 2017 . Apabila ROE semakin tinggi maka semakin baik produktivitas asset dalam memperoleh keuntungan.

\section{SIMPULAN DAN SARAN \\ Simpulan}

Dilihat dari rasio QR menunjukkan bahwa rata-rata Bank BUMN adalah sebesar 0,11 seperti terlihat pada bank BNI 2016 dan 2018, pada BRI dan Bank
Mandiri 2017. Tidak jauh berbeda rata-rata QR pada bank SWASTA juga sebesar 0,11 pada Bank Danamon 2016 dan 2017, Bank MNC tahun 2016, dan Bank Permata tahun 2016.

Rasio BR dari Bank BUMN memperlihatkan perbedaan jumlah ratarata adalah sebesar 0,91 kemudian dibandingkan rata-rata pada Bank SWASTA yang tidak terpaut jauh perbedaannya yaitu sebesar 0,83 .

Rasio LAR dari Bank BUMN adalah sebesar 8,71, sedangkan rata-rata pada Bank SWASTA sebesar 7,64, terdapat selisih sebesar 1,07 persen.

Sedangkan rasio ROE pada Bank BUMN menunjukkan rata-rata sebesar 0,16 dibandingkan dengan jumlah rata-rata Bank SWASTA yang terdapat banyak selisih sebanyak 0,13 yaitu sebesar 0,03.

Saran

Saran dari penulis yaitu Bank Swasta dan Bank BUMN harus lebih mempertahan serta meningkatkan kinerja keuangannya agar lebih berkembang. Untuk Bank MNC dan Bank Permata harus lebih berkembang lagi agar tidak tertinggal dengan Bank Swasta lainnya sehingga dapat bersaing dengan lebih baik lagi dengan banyak bank yang ada hingga saat ini. Hasil penelitian ini dapat digunakan untuk pengembangan ilmu pengetahuan manajemen keuangan khususnya pada bab analisis kinerja keuangan. Penelitian ini dibatasi terbatas hanya pada kinerja keuangan khususnya rasio likuiditas dan profitabilitas, faktor lain dapat dibahas pada penelitian selanjutnya.

\section{DAFTAR PUSTAKA}

Arifin J, S. M. (2006) 'Aplikasi Excel dalam Bisnis Perbankan Terapan'. Jakarta: Elex Media Komputindo, 
Gramedia.

Bawendu, O. R. et al. (2017) 'Analisa Perbandingan Kinerja Keuangan Bank "BUMN" Periode 2011-2015', Jurnal EMBA: Jurnal Riset Ekonomi, Manajemen, Bisnis dan Akuntansi, 5(3), pp. 4265-4274.

Bustari M, Rose R, M. K. (2016) Bank dan lembaga keuangan lain. Edisi 1. Jakarta: KENCANA.

Hantono (2018) Konsep Analisa Laporan Keuangan Dengan Pendekatan Rasio dan SPSS.

Indonesia, R. (1998) 'Undang-undang Republik Indonesia no 10 tahun 1998', in Perubahan Atas Undang Undang No 7 Tahun 1992 Tentang Perbankan. Indonesia: www.bphn.go.id.

Kariyoto (2017) Analisa Laporan Keuangan - Kariyoto - Google Books. Edisi 1, Universitas Brawijaya Press. Edisi 1. Edited by Tim UB Press. Malang: Universitas Brawijaya Press (UB Press).

Sandu, S. and Ali, S. (2015) Dasar Metodologi Penelitian. 1st edn. Edited by Ayup. Yogyakarta: Literasi Media Publishing.

Saragih, J. P. (2017) 'Laporan Kinerja Keuangan Bank Pembangunan Daerah dalam Konteks Transparansi dan Akuntabilitas Keuangan Publik', Jurnal BPPK, 1, pp. 59-70.

Sepang FV, et al (2019) 'Analisis Kinerja Keuangan Dengan Menggunakan Rasio Likuiditas, Solvabilitas Dan Profitabilitas Pada PT. Bank BRI (Persero), Tbk', Simak, 17(01), pp. 18-31.

Sugiono, A. and Untung, E. (2008) PANDUAN PRAKTIS DASAR ANALISA LAPORAN KEUANGAN Pengetahuan Dasar bagi mahasiswa dan praktisi perbankan, Panduan Praktis Dasar Analisa Laporan Keuangan.

Wijaya, D. (2017) 'Manajemen Keuangan Konsep dan Penerapannya', p. 202. https://katadata.co.id/infografik/2020/02/2 4/pertumbuhan-laba-4-bank-bumnmelambat

https://www.wartaekonomi.co.id/read2730 39/dua-jempol-laba-bersih-bca-tetaptumbuh-double-digit-sepanjang-2019

\section{PROFIL SINGKAT}

Lailani Fitria, lahir di Pekanbaru pada tanggal 25 April 1988. Menyelesaikan pendidikan Magister pada Program Studi Manajemen tahun 2013. Saat ini beraktifitas sebagai Dosen Tetap di STIE Tuah Negeri.

Hefi Zuswita, lahir di Anding pada tanggal 03 April 1972. Menyelesaikan pendidikan Magister pada Program Studi Ilmu Administrasi pada tahun 2010. Saat ini beraktifitas sebagai Dosen Khusus di STIE Tuah Negeri.

Rispa Eliza, lahir di Sei Pinang pada tanggal 09 Oktober 1964. Menyelesaikan Program Doktor pada bidang Ilmu Ekonomi tahun 2015. Saat ini beraktifitas sebagai Dosen Tetap di STIE Tuah Negeri. 